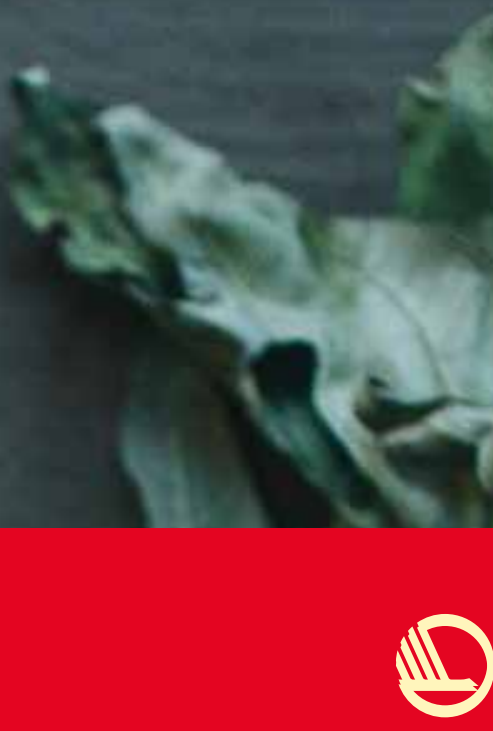

Dreamer's

Guide

An abridged version

of the Solutions Menu:

A Nordic guide to

sustainable food policy 
Dreamer's Guide - An abridged version of the Solutions Menu:

A Nordic guide to sustainable food policy

Editors: Afton Halloran (lead), Mads Frederik Fischer-Møller,

Marie Persson and Elisabet Skylare

\section{US 2018:426}

(c) Nordic Council of Ministers 2018

Layout: ArtRebels

Illustrations: Anna Kövecses

Cover Photo: Natalie Rhea Riggs, unsplash.com

All other photos: Niklas Adrian Vindelev

Print: Rosendahl

Printed in Denmark

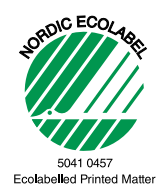

\section{Nordic co-operation}

Nordic co-operation is one of the world's most extensive forms of regional collaboration, involving Denmark, Finland, Iceland, Norway, Sweden, the Faroe Islands, Greenland, and Åland.

Nordic co-operation has firm traditions in politics, the economy, and culture. It plays an important role in European and international collaboration, and aims at creating a strong Nordic community in a strong Europe.

Nordic co-operation seeks to safeguard Nordic and regional interests and principles in the global community. Shared Nordic values help the region solidify its position as one of the world's most innovative and competitive.

\section{Nordic Council of Ministers \\ Nordens Hus \\ Ved Stranden 18 \\ DK-1061 Copenhagen \\ www.norden.org}

Download Nordic publications at www.norden.org/nordpub 


\section{Dreamer's Guide}

An abridged version of the Solutions Menu:

A Nordic guide to sustainable food policy

Download the full version of the Solutions Menu at: norden.org/solutionsmenu 


\section{An insider's}

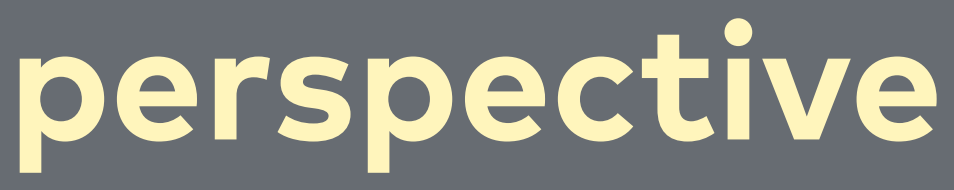

on Nordic

food policy

6 Better nutrition is a collective responsibility

6 How New Nordic became the new normal

6 Placing meals front and centre

8 Taking a bite out of food waste

8 At the frontier of food policy

$8 \quad$ Nordic Food Policy Lab 
What is the best way to make sure that all children have equal access to nutritional food? What are the best ways to instil a greater sense of food culture and identity and what societal benefits can it bring? What is the best way to transition to diets that are better for us and for the health of the planet?

One approach is through food policy.

For the first time, the most innovative food policy solutions in the Nordic Region have been collated in a single document. This Solutions Menu covers nutrition, food culture and identity, public food and meals, food waste and sustainable diets. It includes 24 policy examples - from local, national and regional levels - designed to trigger new conversations and inspire new policies in other parts of the world. Each solution represents a tangible step to address a specific issue; together they represent a new and holistic approach to food policy. They are also testament to the fact that soft policies can deliver solutions and play a significant role in pursuing ambitious national and international goals. 


\section{Better nutrition is a collective responsibility}

The Nordic Nutrition Recommendations form the basis for all Nordic co-operation on nutrition and for national dietary guidelines. A monitoring system provides data on the status of and trends in diet, physical activity and overweight among adults and children. The Keyhole front-of-package nutritional label - used in four of the five Nordic countries - has a solid track record, guiding consumers to make better choices and encouraging the food industry to reformulate their products. Combating negative nutritional trends, like the overconsumption of salt and underconsumption of whole grains, is facilitated by partnerships between public, private and civil society partners. Voluntary nutrition commitments help address the challenges unhealthy diets pose to society. This form of multisectoral partnership also helps consumers make dietary choices that comply with nutritional recommendations.

\section{How New Nordic became the new normal}

The first major sign of political interest in supporting Nordic food culture and identity came after a group of 12 chefs signed the New Nordic Kitchen Manifesto in 2004. Support for bottom-up processes and innovation in the food-service sector have been a priority for Nordic co-operation ever since. National strategies have subsequently been drawn up, using food as a tool not only for attracting tourism, supporting artisans, improving hospitality, national branding and sustainable growth but also to consolidate new principles for Nordic food identity based on sustainability and good health. National resource centres spread information about local food culture, develop capacity to produce artisan food and collate important data about food behaviour trends. At the local government level, councils see food as the next frontier of the creative economy and a way of adding to the urban experience.

\section{Placing meals front and centre}

Mealtimes provide a daily platform to promote better eating habits, engage and educate, as well as to promote social eating. National school meal programmes in the Region date back to the 1940s and now focus on nutritional equality, healthy eating habits and the use of food as a pedagogical tool. The 'Copenhagen model' demonstrates that it is possible to increase the availability and affordability of organic food in public institutions and support the retail market for organic products through the push-pull mechanism of public procurement. Various examples of meal models and labels focus on well-being and nutrition through meals, 


\section{The secret ingredients}

The 24 innovative policy solutions contained in this Solutions Menu have been possible and highly successful because they are:

\section{Evidence-based}

focusing on the most robust and current data at hand

\section{Democratic}

fostering equality by making good food affordable and accessible

\section{Progressive}

promoting innovation and fresh perspectives

\section{Open}

enabling collaboration and dialogue to address complex issues

\section{Holistic}

accounting for the interconnectivities between

policy solutions and global challenges

\section{Sustainable}

safeguarding the health of humankind and the planet

Overall, the policies in the Solutions Menu are non-invasive, i.e. they often meet less resistance because they are co-developed and have multiple benefits for stakeholders involved. 
rather than just the nutritional properties of single food items.

\section{Taking a bite out of food waste}

Civil society has played a significant role in putting food waste on the political agenda. At the Nordic level, the underlying causes of food waste in primary production systems, the potential for food redistribution and the impact of date labelling have been studied in depth. National initiatives are also in place to meet the UN SDG target of $50 \%$ global reduction in food waste at the retail and consumer levels and to reduce food loss in the production and supply chains, including post-harvest losses, by 2030.

Food waste partnerships and networks hold all stakeholders accountable and set ambitious targets.

\section{At the frontier of food policy}

The transition to more sustainable diets is the next frontier for food policy. Governments have only just started to use dietary models to promote human health and the health of the planet. The Nordic Nutrition Recommendations, as well as national dietary guidelines, have started to recommend more plantbased healthy diets that also have less environmental impact. National climate mitigation strategies are also starting to make the much-needed connection between sustainable consumption and production. Despite these efforts, there is a long road ahead. Lessons can be learned from other fields and translated into policies to tackle the problems of tomorrow.

\section{Nordic Food Policy Lab}

The Solutions Menu - A Nordic guide to sustainable food policy is produced by the Nordic Food Policy Lab, one of six flagship projects under the Nordic prime ministers' initiative, Nordic Solutions to Global Challenges. By collecting, curating and sharing Nordic food policy solutions, our aim is to inspire ambitious action on UN Agenda 2030 and the Sustainable Development Goals.

Read on, find inspiration and get in touch to share your ideas and your own policy solutions!

@nordicfoodpol

www.norden.org/foodpolicylab 


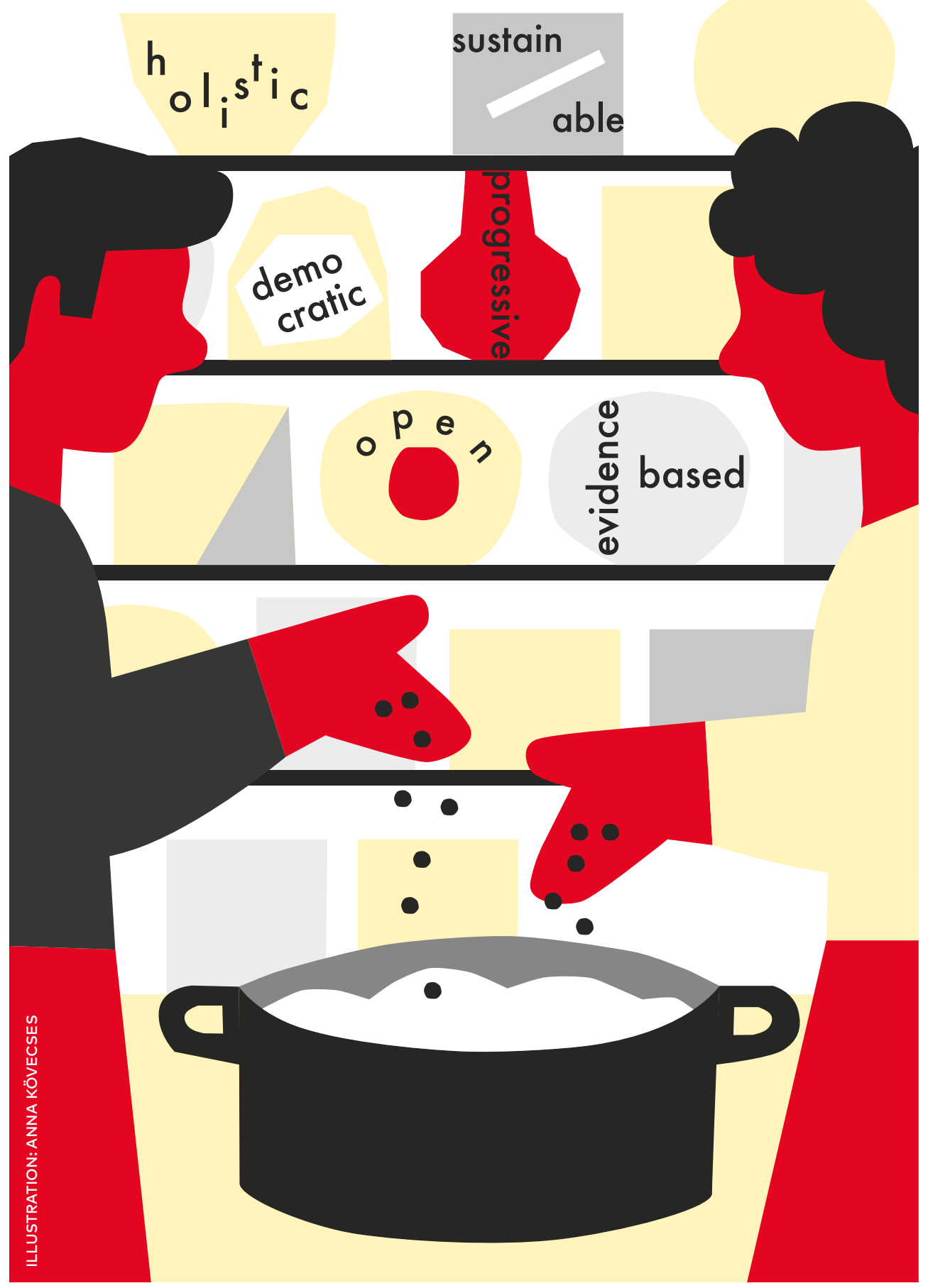

The 'secret ingredients'

The Nordic approaches to food policy are: evidence-based, democratic, progressive, open, holistic and sustainable. 


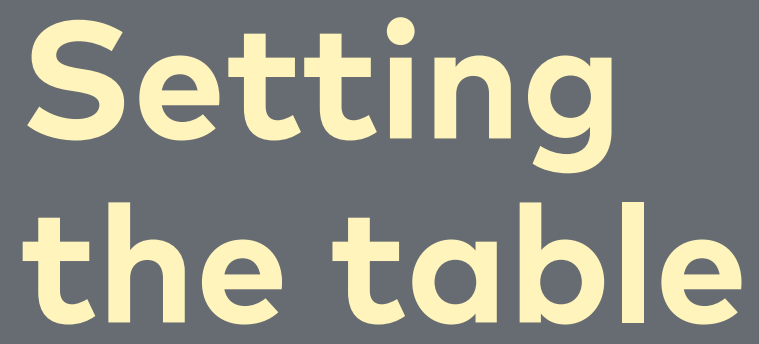

12 Why a solutions menu?

12 Food policy in a Nordic context

14 Why does food policy matter?

17 Who might benefit from the Solutions Menu?

17 What to expect 
When telling the story of food policy in action, it makes sense to start with the humble kale. Kale is a real superfood: sustainable, relatively cheap, packed with vitamins and possible to grow in conditions as low as $-20^{\circ} \mathrm{C}$. However, for decades kale consumption was in decline, abandoned by consumers. Until recently. Today sales of fresh kale are on the rise - alongside cabbage, root vegetables and other Nordic classics. This is just one of many areas where the Nordic countries seem to have turned a corner and begun changing food habits - to the benefit of public health, the environment and the local economies.

The document you are reading will highlight Nordic policy solutions that have been influential in the emergence of a new Nordic food culture. Policies that strengthen the demand for vegetables, whole grains and other healthy, sustainable choices. Policies that aim to limit food waste and the environmental impact of food consumption. And, as you will see, some of them - albeit sometimes behind the scenes - have even helped draw consumers' attention to kale and move it front of mind. 


\section{Why a solutions menu?}

Tackling major global challenges requires multiple tactics. The Solutions Menu is a selection of some of the most innovative food policies coming out of the Nordic countries. This is not about boasting but rather about sharing, inspiring and demonstrating how new policies can bring about change. While the Nordic context may be different from other regional or national contexts, food is a unique way to start conversations about complex issues - something that can really get the ball of progress rolling.

Just as a restaurant menu communicates the selection of food and drink on offer, the Solutions Menu communicates some of the different policies that have been implemented in the Nordic Region. While menus list the available options, what they don't show you is the recipe. In a similar way, policies are context specific; each policy-making context is uniquely different, and each decision-making body has its own recipes for how to devise policy-based solutions to global challenges. As such, the Solutions Menu is an inspirational, living document - one that demonstrates how the Nordic countries have developed policies that respond to societal change and promote sustainable food systems.

Food touches on so many issues, including livelihoods, human and planetary health, identity and economic growth. By addressing issues surrounding food through policy, many double-wins can be achieved, such as job creation and healthier diets or environmentally or climate-friendly meals and improved educational models. The Solutions Menu explains the who, what, where, how, and why behind some of most innovative and timely policies that have been developed in the Nordic Region, in addition to explaining how these policies align with the UN Sustainable Development Goals, the Paris Climate Agreement and other global strategies.

\section{Food policy in a Nordic context}

Food policy solutions come in many shapes and sizes, ranging from government programmes delivering healthy and sustainable school meals, to public-private partnerships on the promotion of healthier products, to support for radical bottom-up innovations that lay the foundations of a new food identity.

The success of Nordic food policy solutions is partly due to the values that underpin the interactions between people, institutions and businesses in the Region, which has comprehensive social safety nets and welfare services, high and equal standards of living, strong civil societies and flat organisational structures that foster trust, individual responsibility and co-operation. These are all undoubtedly factors that play a role in how Nordic food policy solutions are being developed and implemented. But while some tend to focus on Nordic exceptionalism, asserting that the 


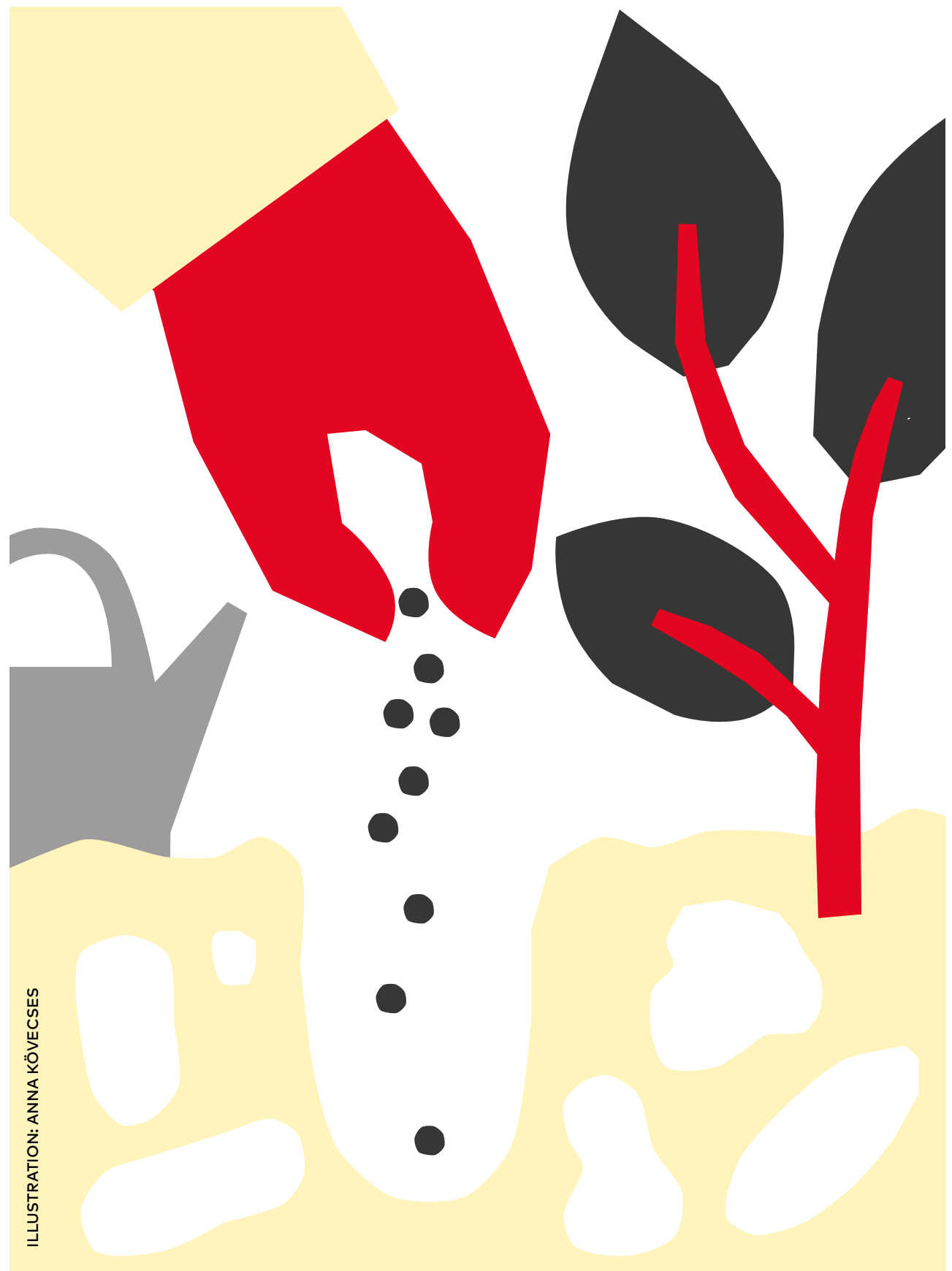

\section{Meeting the challenges}

The five themes contained in the Solutions Menu - nutrition, culture, meals, waste and sustainability - are all interconnected. When done right, food policy can offer an integrated way of tackling global challenges such as climate change, inequality and rapid urbanisation and help create solutions that are cross-cutting and complementary. 
Region has particular societal structures that make it pointless for other countries to seek inspiration and model national policies on examples from this part of the world, we want to emphasise the elements, characteristics and lessons that might inspire other countries and that can be implemented in non-Nordic contexts. As you will find as you go along, many of the examples shared here have universal potential.

It's also worth noting that, in terms of food systems, the Nordic countries hardly constitute a single homogeneous region. On the contrary, the geographical properties of the countries are extremely diverse, ranging from long coastlines with a heavy focus on fishing in the north-west, to open pastures surrounded by dense forests in Finland and the Scandinavian mainland, to vast fields and intensive farming in the south. As a result, we have very different food production systems throughout the Region as well as different approaches to policy objectives in agriculture and fisheries.

In terms of close-to-consumer food policies i.e. policies that are made in close connection to consumers or that directly address consumers, the story is quite different because Nordic consumers expect similarly high standards from their food supply. This report presents a range of innovative policy solutions, all of which are based on shared Nordic approaches which are evidence-based, democratic, progressive, open, holistic and sustainable (see page 9).
In recent years Nordic governments are - with some exceptions - reluctant to use hard policy interventions such as taxation and regulation in tackling the complex problems related to food consumption. Rather, solutions are sought in softer policies through co-operation with the food industry and civil society organisations, and through holistic approaches that use more than one intervention and perspective at the same time. For example, children's health might be targeted by providing foods with improved nutritional value, developing a holistic vision for school meals, providing food education for parents and including information about healthy food choices in physical education. All of which combine to establish a strong basis for kids to make healthier choices.

\section{Why does food policy matter?}

Policy - an invisible yet potent force influences how we access our food, how and what we eat, and even what we throw away. At its most obvious level, it shapes our relationships with food by, for example, preventing us from making unhealthy decisions. Less straightforward, perhaps, is the impact it can have on people and the environment on other continents by setting the standards for trade and the use of natural resources, both near and far. 


\section{What is the Solutions Menu: A Nordic Guide to Sustainable Food Policy meant to achieve?}

1.

\section{Demonstrate}

how the Nordic governments have used policy in response to scientific evidence and/or consumer demands to implement more sustainable and healthy food systems

2.

\section{Highlight}

the momentum that has been created around food policy for sustainable and healthy development in the Nordic countries

3.

\section{Share}

Nordic food policy solutions as an inspiration for national and local governments developing, changing and/or implementing policy related to healthy and sustainable food production and consumption

4.

\section{Ignite}

new conversations, actions and partnerships that create policy-based solutions to sustainable and healthy food systems 


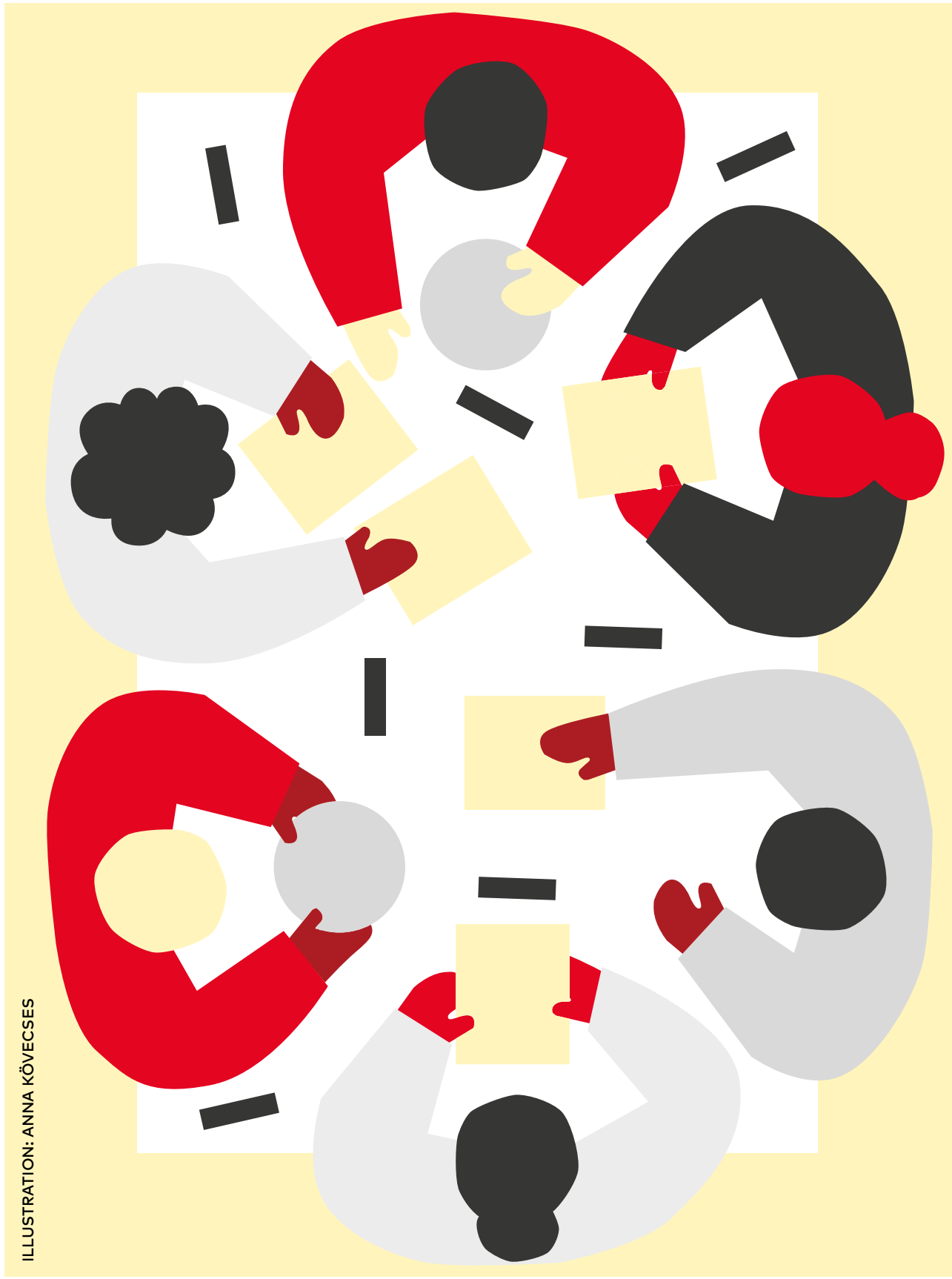

\section{Setting the table}

The inclusion of a wide spectrum of stakeholders is an essential part of developing long-lasting and impactful food policies. Bringing everyone to the table can be challenging given the need to balance and address different perspectives. But as the Solutions Menu shows, dialogue and partnerships can help secure wide-scale buy-in and more robust policies. 
In prosperous periods and times of abundance it is easy to forget how important food policy really is. But looking back over the course of human history, we see how it has dramatically shaped human civilisation. From monarchs to dictators to prime ministers, those unable to provide sufficient food supplies have often been brought down by revolt, revolution or losing elections.

Today, food is tightly intertwined with complex issues like environmental degradation, climate change, cultural identity, animal welfare and health. This means that there are no quick fixes. But when done properly, food policies offer an integrated way to address some of the major global challenges we face. They can help to alter our diet to reduce greenhouse gas emissions, for example, and help to prevent loss of biodiversity and address the rising global threat from non-communicable diseases.

\section{Who might benefit from the Solutions Menu?}

- Governments and ministries seeking inspiration, and behind-the-scenes advice on how to design and execute innovative food-related policies

- International agencies looking for examples of the successful implementation of sustainable food policies that address the UN Sustainable Development Goals

- Researchers from, for example, food-and policy-related disciplines
- Civil society organisations, NGOs, grassroots organisations and special interest groups looking for new ways to shape societal change through food

- Consumers and activists in search of bottom-up policies showcasing the inclusion of a wide range of stakeholder groups

\section{What to expect}

The Solutions Menu features five chapters on different themes: 1) Nutrition; 2) Food culture and identity; 3) Public food and meals; 4) Food waste; and 5) Sustainable diets. Each chapter highlights some of the most innovative, close-to-the-consumer and internationally relevant policy solutions. Each chapter provides a general overview of the history of the solutions as well as the stakeholders involved, the development of the solution, the mechanisms behind it, key characteristics and outcomes. 


\section{New Nordic Kitchen Manifesto}

The Manifesto outlines that New Nordic Cuisine should:

1.

Express the purity, freshness, simplicity and ethics we wish to associate with our Region

2.

Reflect the changes of the seasons in the meals we make

3.

Base cooking on ingredients and produce whose characteristics represent Nordic climates, landscapes and waters

4.

Combine the demand for good taste with modern knowledge of health and well-being

\section{5.}

Promote Nordic products and the variety of Nordic producers, and spread the word about their underlying cultures
6.

Promote animal welfare and a sound production process in our seas, on our farmland and in the wild

\section{7.}

Develop new applications for traditional Nordic food products

8.

Combine the best in Nordic cookery and culinary traditions with inspiration from abroad

9.

Combine self-sufficiency with regional sharing of high-quality products

10.

Join forces with consumer representatives, other culinary craftspeople, farmers, fishermen and women, food, retail and wholesale industries, researchers, teachers, politicians and government bodies on this project for the benefit and advantage of everyone in the Nordic countries 


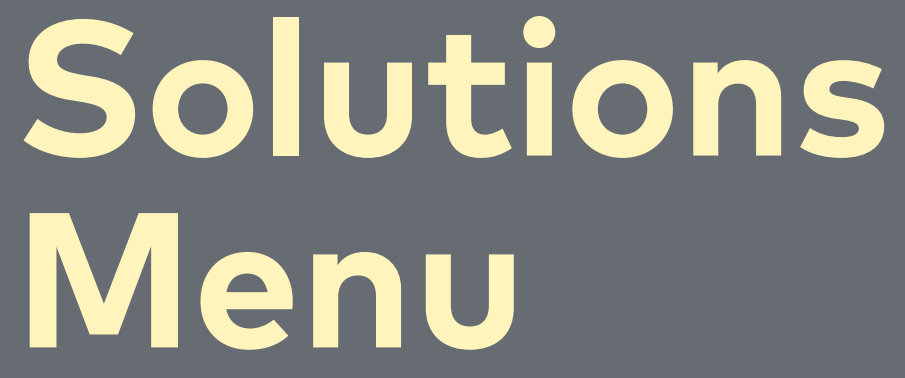

\section{A Nordic guide to sustainable food policy}

\section{Interested in finding out more?}

Download the full version of the Solutions Menu: A Nordic guide to sustainable food policy here: www.norden.org/solutionsmenu 


\section{SETTING THE TABLE}

Why a solutions menu?

Food policy in a Nordic context

Why does food policy matter?

Who might benefit from the Solutions Menu?

What to expect

\section{NORDIC NUTRITION}

Solution \#1: Nordic Nutrition Recommendations (NNR):

Agreement on the facts

Solution \#2: Nordic Plan of Action and the Nordic Monitoring System:

Setting long-term goals

Solution \#3: Keyhole Label: Healthy choices made easy

Solution \#4: Salt partnerships and salt labelling:

Helping the food industry to cut salt

Solution \#5: Whole Grain Partnership::

Expanding the market for whole grains

Solution \#6: Meal initiatives: The next frontier of nutrition policy

Solution \#7: Nutrition commitments:

Broadening the range of healthy food products

Solution \#8: Monitoring food marketing to children:

Halting obesity and overweight

Conclusion: Better nutrition is a shared responsibility

\section{STRENGTHENING FOOD \\ CULTURE AND IDENTITY}

Solution \#9: New Nordic Food: Building a regional food identity

Solution \#10: National strategies:

Capitalising on new Nordic food culture

Solution \#11: National gastronomic resource centres:

Democratising good food

Solution \#12: Local food culture strategies:

Supporting the experience economy

Conclusion: New Nordic is now the new normal 


\section{PUBLIC FOOD AND MEALS}

Solution \#13: Universal school meal programmes:

Establishing nutritional equality

Solution \#14: Local government procurement of organic food:

Implementing the 'Copenhagen model'

Solution \#15: Organic strategies for public-sector meals:

Setting ambitious goals

Solution \#16: Public meal models: Delivering on multiple societal goals

Solution \#17: The Danish Meal Label: Making meals eaten

outside the home nutritious and delicious

Solution \#18: Hospital meals: Improving the patient experience

Conclusion: Putting meals front and centre

\section{CUTTING DOWN ON FOOD WASTE}

Solution \#19: Nordic initiatives:

Understanding the dynamics of food waste

Solution \#20: National food waste strategies:

Tackling unsustainable consumption patterns

Solution \#21: Nordic food waste networks:

Encouraging collaboration throughout the supply chain

Conclusion: Seeing an opportunity in every challenge

\section{SUSTAINABLE DIETS: \\ WHAT'S NEXT FOR \\ NORDIC FOOD POLICY?}

Solution \#22: Dietary guidelines: Holistic approaches to healthy and environmentally sustainable diets

Solution \#23: Climate smart models:

Reducing the environmental impact of meals

Solution \#24: Finnish Climate Programme:

Linking sustainable production and consumption

Conclusion: Looking into the future of food policy 


\section{When it comes to making our food systems more sustainable, we see food as a catalyst for climate action}

Katrín Jakobsdóttir

Prime Minister of Iceland 


\section{Join the \\ conversation \\ @nordicfoodpol \\ \#nordicsolutions}

Nordic Food Policy Lab is part of Nordic Solutions to Global Challenges, a joint initiative by the prime ministers of the Nordic countries.

We collect and curate Nordic food policy solutions, responding to the UN Agenda 2030 and the UN Sustainable Development Goals (SDGs). We invite others to join forces with us and set up global partnerships to showcase and spread the use of innovative, close-to-the-consumer policies promoting sustainable and healthy food choices.

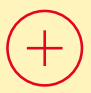

Sign up to our newsletter: norden.org/foodpolicynews For regular updates follow us on Twitter: @nordicfoodpol You can also stay updated about our work via: norden.org/foodpolicylab 
Nordic Council of Ministers

Nordens Hus

Ved Stranden 18

DK-1016 Copenhagen

www.norden.org

\section{Solutions Menu - A Nordic guide to sustainable food policy} For the first time, the most innovative food policy solutions in the Nordic Region have been brought together in a single document. The Solutions Menu includes 24 policies that aim to change food consumption and intends to inspire new and robust policy responses to the societal and environmental challenges caused by our current food systems.

The Solutions Menu is produced by the Nordic Food Policy Lab, one of six flagship projects under the Nordic prime ministers' Nordic Solutions to Global Challenges initiative.

This version, the Dreamer's Guide, is an abridged version of the Solutions Menu: A Nordic guide to sustainable food policy.

Download the digital version: norden.org/solutionsmenu 